\title{
Radiosurgery for Medial Temporal Lobe Epilepsy Resulting from Mesial Temporal Sclerosis
}

\author{
Thomas Gianaris, MD \\ Indiana University School of Medicine, Indianapolis, IN \\ Thomas Witt, MD \\ Neurosurgery, Indiana University Health, Indianapolis, IN \\ Nicholas M. Barbaro, MD \\ Professor and Chair, Neurological Surgery, Indiana University, Indianapolis, IN \\ CORRESPONDENCE: \\ Nicholas M. Barbaro, MD \\ 355 W 16th Street \\ Suite 5100 \\ Indianapolis, IN 46202 \\ Nbarbaro@iupui.edu
}

SYNOPSIS: Mesial temporal lobe epilepsy associated with mesial temporal sclerosis (MTS) is perhaps the most well-defined epilepsy syndrome that is responsive to structural interventions such as surgery.

When temporal lobe epilepsy is caused by underlying MTS, seizure improvements with open

microsurgical resections have been reported in $65-90 \%$ of patients $[5,7,23-27]$. Though morbidity and mortality in these procedures are typically low, open resection, as with any open technique, is associated with an increased risk of infection, blood loss, ischemic events, and postoperative hemorrhage, as well as prolonged hospital stay. Several clinical studies evaluating the morbidity and mortality associated with open microsurgery for temporal lobe epilepsy have reported that approximately $5 \%$ to $23 \%$ of patients experience a postoperative symptomatic neurological deficit $[8,11,12,15,16]$. In recent years, several minimally invasive techniques have arisen that provide 
additional options for the treatment of MTS while potentially avoiding many of open surgery's

associated risks. By evading these risks, they also open up treatment options to patients that would

otherwise be poor surgical candidates based on tumor size or location $[6,19]$. Radiosurgery is one of the

most intensively studied of these alternatives and has found a growing role in the treatment of medial

temporal lobe epilepsy.

\section{KEY POINTS:}

- Radiosurgery for mesical temporal sclerosis (MTS)-associated medial temporal love epilepsy (MTLE) is an attractive option because it is relatively noninvasive, with lower morbidity than major surgery.

- Conventional open temporal lobectomy surgery may also be pursued if the initial radiosurgical treatment is ineffective and after sufficient time has been permitted for the delayed radiosurgical antiepileptic effect after 3 years.

- The main known disadvantage of radiosurgery at present is the delayed response for seizure control, during which time patients continue to suffer from the sequelae of seizures.

- Future research into this treatment modality will ideally make individualized patient treatment more feasible and attainable, allowing the neurosurgical community to more effectively manage and treat medial temporal lobe epilepsy. 


\section{Introduction}

Radiosurgery is the precise application of focused radiation to targeted brain with the aid of stereotactic guidance [1-27]. Radiosurgery is particularly well suited for treatment of MTS leading to medial temporal lobe epilepsy because MTS typically exhibits radiographic changes on MRI, allowing this focused radiation to be directed to a specific, small region of pathology, sparing the rest of the brain from harmful radiation [24]. Regis and colleagues were able to demonstrate the safety of focused radiosurgery for medial temporal lobe epilepsy while still delivering doses effective enough to reduce seizure frequency, whereas a prospective multicenter European study using the Gamma Knife proprietary radiosurgery tools found similar efficacy rates for seizure reduction with a dose of $29 \mathrm{~Gy}$ when comparing radiosurgery to the gold standard of conventional microsurgery for epilepsy after 2 years with similar morbidity and mortality [28].

A similar multicenter trial studying a direct comparison of radiosurgery to resection for MTLE has shown in pilot studies that a dose of 24 Gy to the medial temporal lobe was able to eliminate seizures in $85 \%$ of patients at 2 years of follow up as well [29]. In this pilot study, patients were treated with 2 different radiation doses ( 20 or $24 \mathrm{~Gy}$ ) and there was significant seizure remission in both groups at 12 months (58.8\% and $76.9 \%$ respectively), with no dose-based or seizure remission-based changes in headaches, visual field defects, and the use of steroids. Although these studies thus far only have time points at 1 and 2 years, recent research in France looking at outcomes of 5 and 8 years has demonstrated continued seizure reduction remission after radiosurgery, although at a lower rate, finding $47 \%$ remission at 5 years and $60 \%$ at 8 years [30,31]. In addition, there may be benefits with respect to memory and language preservation. 


\section{Risks of Treatment}

Although these studies have shown that radiosurgery is effective with minimal morbidity and mortality at time points of greater than one year, radiosurgery, unlike open resection, has a lag time after treatment before patients begin to see the effects of therapy and, in the near-term, patients are still exposed to the risks of continued seizures as well as the risks of radiation. Typically, patients treated with radiosurgery can achieve seizure reduction at 9-12 months and possible complete cessation of seizures between 18 and 24 months after radiosurgery treatment [28]. In addition, a transient increase

in partial seizures (auras) can be noted at approximately the same time that complex seizures decrease with radiosurgery and many of them require a transient period of steroid administration for the radiation-induced edema [28]. Srikijvilaikul and colleagues found two deaths during this latency period in a small case series of five patients treated with $20 \mathrm{~Gy}$ before seizure remission, likely complications of ongoing seizures [33]. Quigg and colleagues found that language (Boston Naming Test), verbal memory (California Verbal Learning Test and Logical Memory Subtest of the Wechsler Memory Scale-Revised), cognitive efficiency, and mental flexibility (Trail Making Test), and mood (Beck Depression Inventory) did not differ from baseline after radiosurgery, demonstrating long-term neurocognitive safety using established scoring scales, despite the increased potential for necrosis [33].

Radiosurgery for MTLE is not without risks and long-term effects; radiation necrosis has been demonstrated by several studies and case reports. Hensley-Judge and colleagues [34] found postoperative visual field deficits in 15 of 24 (62.5\%) patients, all homonymous superior quadrantanopsias, proportions similar to historical comparisons from open surgery for MTLE. Another case series demonstrated two of seven patients, status post radiosurgery for MTS presenting with symptomatic radiation necrosis, required resection after 5 and 10 years [35]. Additionally, there is some concern in the long term for radiosurgery-associated 'radiation-induced' malignancies, though these 
reported cases are rare, and none has been reported following therapy for MTS [36-39]. While it has initially been studied as a primary modality for MTS treatment, radiosurgery is also being investigated as a treatment for refractory epilepsy after temporal lobe resection. Yen and colleagues found significant seizure reduction in a case series of 4 patients who underwent radiosurgery following temporal lobe resection[40]. There was reduction of seizure frequency at 6 months after radiosurgery for refractory epilepsy after temporal lobe resection as well as improved neuropsychological profiles, including memory function and quality of life, lasting up to the 2-year follow-up exam.

\section{Mechanism of Action and Histopathology}

Conversely, open resective surgery following radiosurgery has, as a side benefit, provided an opportunity to understand the mechanism of action of radiosurgery on a histopathologic level. In two separate studies, Kawai and colleagues and Srikijvilaikul and colleagues found histologic changes, including necrotic foci with vessel wall thickening and fibrinoid and hyaline degeneration, in a patient treated with $18 \mathrm{~Gy}$, as well as perivascular sclerosis, and macrophage infiltration upon resection and evaluation of a patient treated with $20 \mathrm{~Gy}[32,41]$. Cmelak and colleagues reported no radiationinduced histopathologic changes in tissues treated with 15 Gy of radiosurgery, suggesting that some histological damage may be needed for effective seizure control [42-45]. Chang and colleagues found vasogenic edema appeared approximately 9-12 months after radiosurgery on serial MRI scans and correlated with the onset of seizure remission, further corroborating this hypothesis [46]. Barbaro and and colleagues suggested that the mechanisms may be some combination of neuromodulation and true neuronal destruction, with some animal studies demonstrating improvement in seizures without evidence of necrosis, whereas others have shown direct structural, destructive lesions in the tissue zone to correlate better with outcome, perhaps because of some contribution from ischemic factors $[29,446$, 47]. The concrete mechanism of radiosurgery, destructive or otherwise, warrants further study. 


\section{Summary}

In summary, radiosurgery for MTS-associated MTLE is an attractive option because it is relatively

noninvasive, with lower morbidity than major surgery. Conventional open temporal lobectomy surgery

may also be pursued if the initial radiosurgical treatment is ineffective and after sufficient time has been

permitted for the delayed radiosurgical antiepileptic effect after 3 years [28]. Its main known disadvantage

at present is the delayed response for seizure control, during which time patients continue to suffer from

the sequelae of seizures. Future research into this treatment modality will ideally make individualized

patient treatment more feasible and attainable, allowing the neurosurgical community to more

effectively manage and treat medial temporal lobe epilepsy.

\section{REFERENCES}

1. Engel J Jr. Surgery for seizures. N Engl J Med 1996;

334:647-52.

2. Wiebe S, Blume WT, Girvin JP, et al, Effectiveness, Efficiency of Surgery for Temporal Lobe Epilepsy

Study Group. A randomized, controlled trial of surgery

for temporal-lobe epilepsy. N Engl J Med

2001;345:311-8.

3. Bien CG, Kurthen M, Baron K, et al. Long-term

seizure outcome and antiepileptic drug treatment

in surgically treated temporal lobe epilepsy patients:

a controlled study. Epilepsia 2001;42:1416-21.

4. Cascino GD. Clinical correlations with hippocampal

atrophy. Magn Reson Imaging 1995;13:1133-6.

5. Cascino GD. Structural neuroimaging in partial epilepsy.

Magnetic resonance imaging. Neurosurg

Clin N Am 1995;6:455-64.

6. Engel J Jr. Update on surgical treatment of the epilepsies.

Summary of the Second International Palm

Desert Conference on the Surgical Treatment of

the Epilepsies (1992). Neurology 1993;43:1612-7.

7. Garcia PA, Laxer KD, Barbaro NM, et al. Prognostic value of qualitative magnetic resonance imaging

hippocampal abnormalities in patients undergoing temporal lobectomy for medically refractory seizures. 
Epilepsia 1994;35:520-4.

8. Spencer SS. Long-term outcome after epilepsy surgery.

Epilepsia 1996;37:807-13.

9. Spencer SS, Berg AT, Vickrey BG, et al. Predicting

long-term seizure outcome after resective epilepsy

surgery: the multicenter study. Neurology 2005;65:

912-8.

10. Spencer SS, Berg AT, Vickrey BG, et al. Initial outcomes

in the Multicenter Study of Epilepsy Surgery.

Neurology 2003;61:1680-5.

11. Behrens E, Schramm J, Zentner J, et al. Surgical

and neurological complications in a series of 708

epilepsy surgery procedures. Neurosurgery 1997;

41:1-9 [discussion: 9-10].

12. Rydenhag B, Silander HC. Complications of epilepsy

surgery after 654 procedures in Sweden,

September 1990-1995: a multicenter study based

on the Swedish National Epilepsy Surgery Register.

Neurosurgery 2001;49:51-6 [discussion: 56-7].

13. Siegel AM, Cascino GD, Meyer FB, et al. Surgical

outcome and predictive factors in adult patients with

intractable epilepsy and focal cortical dysplasia.

Acta Neurol Scand 2006;113:65-71.

14. Sperling MR, Feldman H, Kinman J, et al. Seizure

control and mortality in epilepsy. Ann Neurol 1999;

46:45-50.

15. Guldvog B, Loyning Y, Hauglie-Hanssen E, et al.

Surgical versus medical treatment for epilepsy. II.

Outcome related to social areas. Epilepsia 1991;

32:477-86.

16. Guldvog B, Loyning Y, Hauglie-Hanssen E, et al.

Surgical versus medical treatment for epilepsy. I.

Outcome related to survival, seizures, and neurologic

deficit. Epilepsia 1991;32:375-88.

17. Barcia Salorio JL, Roldan P, Hernandez G, et al. Radiosurgical

treatment of epilepsy. Appl Neurophysiol

1985;48:400-3.

18. Barcia-Salorio JL, Vanaclocha V, Cerda M, et al.

Response of experimental epileptic focus to focal

ionizing radiation. Appl Neurophysiol 1987;50:359-64.

19. Kitchen N. Experimental and clinical studies on the putative therapeutic efficacy of cerebral irradiation

(radiotherapy) in epilepsy. Epilepsy Res 1995;20:

$1-10$.

20. Sun B, DeSalles AA, Medin PM, et al. Reduction of

hippocampal-kindled seizure activity in rats by stereotactic 
radiosurgery. Exp Neurol 1998;154:691-5.

21. Herynek V, Burian M, Jirak D, et al. Metabolite and

diffusion changes in the rat brain after Leksell

Gamma Knife irradiation. Magn Reson Med 2004;

52:397-402.

22. Jirak D, Namestkova K, Herynek V, et al. Lesion evolution

after gamma knife irradiation observed by

magnetic resonance imaging. Int J Radiat Biol

2007;83:237-44.

23. Mori Y, Kondziolka D, Balzer J, et al. Effects of stereotactic

radiosurgery on an animal model of hippocampal

epilepsy. Neurosurgery 2000;46:157-65

[discussion: 165-8].

24. Dillon WP, Barbaro N. Noninvasive surgery for epilepsy:

the era of image guidance. AJNR Am J Neuroradiol

1999;20:185.

25. Kondziolka D, Lunsford LD, Witt TC, et al. The future

of radiosurgery: radiobiology, technology, and applications.

Surg Neurol 2000;54:406-14.

26. Nguyen DK, Spencer SS. Recent advances in the

treatment of epilepsy. Arch Neurol 2003;60:929-35.

27. Cohen-Gadol AA, Wilhelmi BG, Collignon F, et al.

Long-term outcome of epilepsy surgery among

399 patients with nonlesional seizure foci including

mesial temporal lobe sclerosis. J Neurosurg 2006;

104:513-24.

28. Regis J, Rey M, Bartolomei F, et al. Gamma knife surgery

in mesial temporal lobe epilepsy: a prospective

multicenter study. Epilepsia 2004;45:504-15.

29. Barbaro NM, Quigg M, Broshek DK, et al.

A multicenter, prospective pilot study of gamma

knife radiosurgery for mesial temporal lobe epilepsy: seizure response, adverse events, and verbal memory. Ann Neurol 2009;65:167-75.

30. Bartolomei F, Hayashi M, Tamura M, et al. Long-term

efficacy of gamma knife radiosurgery in mesial temporal

lobe epilepsy. Neurology 2008;70:1658-63.

31. Rheims S, Fischer C, Ryvlin P, et al. Long-term

outcome of gamma-knife surgery in temporal lobe

epilepsy. Epilepsy Res 2008;80:23-9.

32. Srikijvilaikul T, Najm I, Foldvary-Schaefer N, et al.

Failure of gamma knife radiosurgery for mesial temporal

lobe epilepsy: report of five cases. Neurosurgery

2004;54:1395-402 [discussion: 1402-4].

33. Quigg M, Broshek DK, Barbaro NM, et al. Neuropsychological

outcomes after Gamma Knife radiosurgery 
for mesial temporal lobe epilepsy: a

prospective multicenter study. Epilepsia 2011;52:

909-16.

34. Hensley-Judge H, Quigg M, Barbaro NM, et al. Visual

field defects after radiosurgery for mesial temporal

lobe epilepsy. Epilepsia 2013;54:1376-80.

35. Usami K, Kawai K, Koga T, et al. Delayed complication

after Gamma Knife surgery for mesial temporal

lobe epilepsy. J Neurosurg 2012;116:1221-5.

36. Shamisa A, Bance M, Nag S, et al. Glioblastoma

multiforme occurring in a patient treated with

gamma knife surgery. Case report and review of

the literature. J Neurosurg 2001;94:816-21.

37. Kaido T, Hoshida T, Uranishi R, et al. Radiosurgeryinduced

brain tumor. Case report. J Neurosurg

2001;95:710-3.

38. Ganz JC. Gamma knife radiosurgery and its

possible relationship to malignancy: a review.

J Neurosurg 2002;97:644-52.

39. Quigg M, Rolston J, Barbaro NM. Radiosurgery for epilepsy: clinical experience and potential antiepileptic mechanisms. Epilepsia 2012;53:7-15.

40. Yen DJ, Chung WY, Shih YH, et al. Gamma knife radiosurgery

for the treatment of recurrent seizures after

incomplete anterior temporal lobectomy. Seizure

2009;18:511-4.

41. Kawai K, Suzuki I, Kurita H, et al. Failure of low-dose

radiosurgery to control temporal lobe epilepsy.

J Neurosurg 2001;95:883-7.

42. Cmelak AJ, Abou-Khalil B, Konrad PE, et al. Lowdose

stereotactic radiosurgery is inadequate for

medically intractable mesial temporal lobe epilepsy:

a case report. Seizure 2001;10:442-6.

43. Regis J, Peragui JC, Rey M, et al. First selective

amygdalohippocampal radiosurgery for 'mesial temporal

lobe epilepsy'. Stereotact Funct Neurosurg

1995;64(Suppl 1):193-201.

44. Regis J, Bartolomei F. Comment on: failure of

gamma knife radiosurgery for mesial temporal lobe

epilepsy: report of five cases. Neurosurgery 2004;

54:1404.

45. Regis J, Bartolomei F, Rey M, et al. Gamma knife

surgery for mesial temporal lobe epilepsy. Epilepsia

1999;40:1551-6.

46. Chang EF, Quigg M, Oh MC, et al. Predictors of efficacy

after stereotactic radiosurgery for medial temporal 
lobe epilepsy. Neurology 2010;74:165-72.

47. Yu JS, Yong WH, Wilson D, et al. Glioblastoma induction after radiosurgery 